\title{
Pancreatic Poorly Differentiated Ductal Adenocarcinoma
}

National Cancer Institute

\section{Source}

National Cancer Institute. Pancreatic Poorly Differentiated Ductal Adenocarcinoma. NCI

Thesaurus. Code C95428.

A pancreatic ductal adenocarcinoma characterized by the presence of small and irregular malignant glandular structures, solid sheets of malignant cells, and single malignant cells. 